\title{
Development and Validation of an Environmentally Benign and Robust Stability Indicating Assay Method for Lenalidomide: Comprehensive Degradation Kinetics Study and Application of Synergistic Approach Involving Green Analytical Chemistry and Quality by Design Methodology
}

\author{
Juhi Saxena, Seema Saroj, Priya Virendrakumar Shah, Sadhana Rajput* \\ Pharmaceutical Quality Assurance Laboratory, Centre for Relevance and Excellence in Novel Drug Delivery Systems, Faculty of \\ Pharmacy, The Maharaja Sayajirao University of Baroda, G.H. Patel Pharmacy Building, Fatehgunj, Vadodara-390002, Gujarat, INDIA.
}

\begin{abstract}
Objective: A state of the art, robust and environmentally benign stability indicating assay method (SIAM) has been developed for model drug Lenalidomide (LEN). Methods: A Green metrics assessment was conducted by environment assessment tool (EAT), analytical method volume intensity (AMVI) and Ecosolvent tool. Successful chromatographic separation was accomplished on a Thermo C18 GAC column having dimensions of $4.6 \times 150 \mathrm{~mm}$ and $3 \mu$ particle size using green solvents viz., methanol and acetate buffer in the ratio of 85:15. Results: The obtained EAT score and AMVI were 32.19 and 24 $\mathrm{mL}$ respectively. A green SIAM was developed and it was validated as per ICH Q2 (R1) guidelines. Quality by Design ( $\mathrm{QbD}$ ) approach was incorporated at validation stage to prove the robustness of the developed green method by applying $2^{\wedge 5-2}$ Res III 2 - level fractional factorial design (FFD). Conclusion: An extensive stress degradation study along with degradation kinetics were performed and probable degradation pathways were predicted.
\end{abstract}

Key words: Lenalidomide, Green analytical chemistry, Quality by Design, Degradation kinetics, LC-MS/MS.

\section{INTRODUCTION}

With the advent of new technologies and techniques in the field of analytical chemistry, it has become necessary to study their impact on the environment as well. With the large amount of solvent waste generated in all techniques, it is of prime importance to ensure that their negative impact on the environment is minimized and use of environmentally benign solvents is encouraged. Green analytical chemistry (GAC) is a part of green chemistry and is principally based on the traditional concept of 3R's, i.e. 'reduce', 'replace' and 'recycle'. The green metrics assessment includes EAT
(Environment assessment tool), AMVI (Analytical method volume intensity) and treatment option score given by the Ecosolvent ${ }^{\circledR}$ tool. ${ }^{2-3}$ The EAT tool considers all three aspects of Environment, health and safety and gives the score for same. ${ }^{2}$ The lower EAT score indicates an environment friendly method. Notably, narrow bore columns have a prima facie role to play here. The GAC column length and particle size are lesser in contrast to commonly used reverse phase high performance chromatography (RP-HPLC) columns having a column length of $250 \mathrm{~mm}$ and particle size of $5 \mu$.
Submission Date: 14-03-2018; Revision Date: 05-06-2018; Accepted Date: 14-08-2018

DOI: 10.5530/ijper.53.1.18

Correspondence:

Prof (Mrs.) Sadhana J.

Rajput,

Quality Assurance Laboratory, Centre of Relevance and Excellence in Novel Drug Delivery Systems, Pharmacy department, Shri G.H. Patel Building, Donor's plaza, The Maharaja Sayajirao University of Baroda,

Fatehgunj,

Vadodara-390002, Gujarat, INDIA.

Phone: +91-9998309662

E-mail: sjrajput@gmail.com

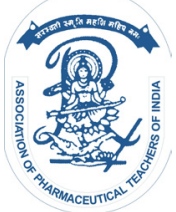

www.ijper.org 
Amongst the numerous benefits of GAC, lowering in solvent consumption is most important. Commonly used RP-HPLC organic solvents include methanol $(\mathrm{MeOH})$ and acetonitrile $(\mathrm{ACN})$ where, $\mathrm{MeOH}$ is quite greener and environmentally benign with respect to ACN which has a more negative impact on the environment. This statement is based on the solvent selection guide (SSG) published by the GSK ${ }^{\circledR}$ (Glaxo Smith Kline) which has categorised solvents into different regions differentiated by color coding. Herein green color represents environmentally friendly solvents having negligible impact on the environment, yellow includes solvents with intermediate effect and solvents in the red region are the ones we must avoid to use in HPLC..$^{45} \mathrm{MeOH}$ is included under the green solvent category. The firm foundation for this is laid based on the life cycle assessment of solvents.

Quality by design (QbD) methodology is being widely used in method development and validation to optimize and develop a robust method which can provide a great ease in analytical method transfer, eliminating the need for re-validation. It is based on the Design of experiments (DoE) methodology. It can be applied at 3 stages of method development. Initially at a screening of parameters where fractional factorial Res III, Taguchi and Placket Burman designs are implemented. Secondly, DoE is used during method optimization by employing Box Benken and Central Composite Design. ${ }^{6}$ Lastly, it is also used to check the robustness of the developed method adopting fractional factorial Res IV and Placket Burman designs. In the present work DoE has been employed in checking the robustness of the developed method. The design employed was $2^{\wedge 5-2}$ Res III 2 level fractional factorial design. Design expert ${ }^{\mathbb{R}}$ 7.0.0 software was used for this purpose. Application of both the concepts of GAC and QbD together gives a synergistic benefits of a robust and green method. ${ }^{7-8}$

Lenalidomide (LEN) is a highly potent anticancer drug administered orally at the dose of 5,10 and $25 \mathrm{mg}$ in capsule formulation. It is a biologically more active derivative of Thalidomide, used in the treatment of multiple myeloma and mantle cell lymphoma. ${ }^{9}$ Additionally, it has also been successfully used in treating anaemia caused by certain bone marrow disorders. ${ }^{10}$ Chemically, it is 3-(4- amino-1-Oxo 1, 3-dihydro2H-isoindol-2-yl) piperidine- 2, 6-Dione. ${ }^{11}$ It also contains sensitive groups as seen in the structure (Figure 1) and hence it was thought of considerable interest to study the degradation pathways and degradation kinetics in various conditions by a robust and environmentally benign RP-HPLC method. Though, there have been various methods available for LEN estimation, so far,

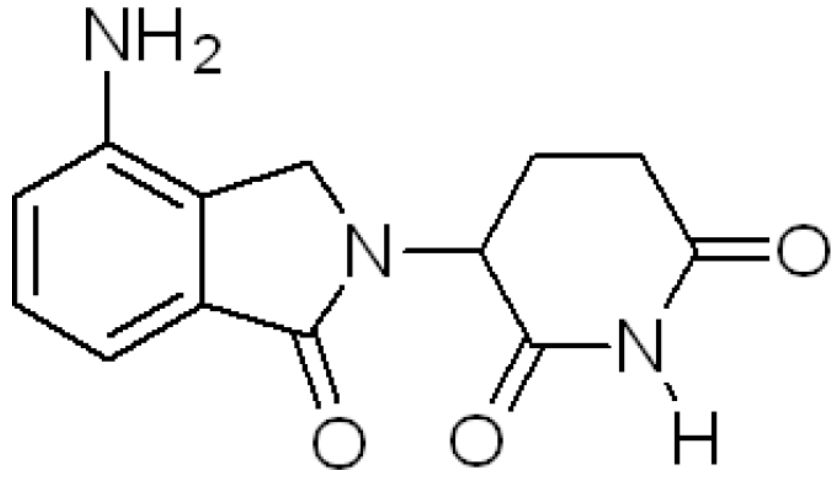

Figure 1: Chemical Structure of Lenalidomide (LEN).

to the best of our knowledge, there has not been any green method which involves combined application of GAC and QbD. ${ }^{12-15}$ Most of these methods used ACN for method development which is not considered to be an environmentally favourable solvent or having complex mobile phase with high EAT scores. The present manuscript describes the involvement of two concepts GAC and QbD in method development and validation taking LEN as a model drug. The stability indicating assay method (SIAM) developed here included buffer and $\mathrm{MeOH}$ in the ratio 85:15, which is highly favourable from an environmental point of view and economically superior as well. The extensive degradation study in presence of varied stressors displayed acid and alkali labile nature of LEN with formation of two degradation products (DPs) which were separated from the drug with the resolution of more than 2 units.

\section{MATERIALS AND METHODS}

\section{Chemicals and reagents}

LEN an active pharmaceutical ingredient (API) was kindly gifted by Apicore Pharmaceutical Ltd (Vadodara, India). Various analytical grade chemicals used in the stress degradation like, hydrochloric acid $(\mathrm{HCl})$, sodium hydroxide $(\mathrm{NaOH})$, hydrogen peroxide $\left(\mathrm{H}_{2} \mathrm{O}_{2}\right)$, ammonium acetate and acetic acid were purchased from Loba Chemie Pvt. Ltd. HPLC grade Methanol $(\mathrm{MeOH})$ was procured from Rankem Pvt. Ltd. Double distilled water was used throughout the study. All the solutions were filtered through a $0.2 \mu$ filter Ultipor ${ }^{\circledR} \mathrm{N} 66^{\circledR}$ Nylon membrane filter (Pall Life Sciences, USA).

\section{Chromatographic System and Conditions}

The chromatographic method was carried out on a Shimadzu LC system equipped with Shimadzu LC-20AT pump and Shimadzu SPD-20AV detector (Kyoto, Japan). Samples were injected through a Rheodyne 7725 injector 
valve with fixed loop at $20 \mu \mathrm{L}$ and the data acquisition and integration was executed on Spinchrome software ${ }^{\circledR}$ (Spinco Biotech, Vadodara). A stress degradation study was carried out using a silicon oil bath having temperature adjustable knob facility. The $\mathrm{pH}$ meter (Lab India, India) was used to check $\mathrm{pH}$ of all solutions. Other equipments used were sonicator (ePEI ultrasonic generator), electronic analytical balance $(A \times 120$, Shimadzu), hot air oven (Tempo Instrument and equipment Pvt Ltd, India.) and auto pipettes (Eppendorf, Hamburg, Germany). Furthermore, the photolytic study was carried out using photo chamber. The LC-MS/MS experiment was performed on 3200 QTRAP LC-MS/MS instrument (AB Sciex instruments,) equipped with a binary pump LC system, Ekspert 100-XL Auto sampler, Ekspert 100 Pump, Ekspert 100 Column Oven and Quadrapole mass analyser. Waters ${ }^{\circledR} \mathrm{C} 18$ column $(250 \times 4.6 \mathrm{~mm}, 5 \mu)$ and narrow bore Thermo Scientific ${ }^{\circledR}$ C18 column having dimension of $150 \times 4.6 \mathrm{~mm}, 3 \mu$ were used for evaluation of greenness employing three dedicated approaches vir., EAT, ecosolvent approach, and AMVI. The data acquisition was performed through Analyst software ${ }^{\circledR}$ (version 1.6.2). Degradation mechanism was studied in depth using mass spectrometry method. Design Expert $^{\circledR}$ 7.0.0 software $\left(\mathrm{DX}^{\circledR}\right.$ 7.0.0) was used to obtain DoE design matrix.

\section{Preparation of mobile phase}

Varied number of trials were executed utilizing different buffer systems (ammonium acetate, potassium dihydrogen phosphate, ammonium formate) in a $\mathrm{pH}$ range of 3 to 5.5 and organic modifier $(\mathrm{MeOH})$. The final optimized method had the mobile phase composition of ammonium acetate buffer and $\mathrm{MeOH}$. Here, $10 \mathrm{mM}$ ammonium acetate having a $\mathrm{pH}$ of 5 adjusted with acetic acid was prepared. Finally, the solution was filtered through $0.2 \mu$ Nylon membrane filter. This aqueous phase was mixed with an organic phase $(\mathrm{MeOH})$ in the ratio of 85:15.

\section{Preparation of LEN Stock solution, working solution and calibration curve solutions}

$10 \mathrm{mg}$ of LEN was weighed accurately and transferred into a $10 \mathrm{~mL}$ volumetric flask containing $1 \mathrm{~mL}$ methanol. The API was dissolved after sonicating the drug solution and volume was made up to the mark using methanol to obtain a LEN stock solution with the concentration of $1000 \mu \mathrm{g} / \mathrm{mL}$. Working standard solution of LEN having concentration of $100 \mu \mathrm{g} / \mathrm{mL}$ was prepared from stock solution. Working solution of $100 \mu \mathrm{g} / \mathrm{mL}$ was utilized further, to prepare calibration curve solutions ranging from $4,8,12,16,20$ and $24 \mu \mathrm{g} / \mathrm{mL}$ by withdrawing 0.4 ,
$0.8,1.2,1.6,2.0$ and $2.4 \mathrm{~mL}$ respectively, followed by analysis at $\lambda_{\text {max }} 250 \mathrm{~nm}$ in HPLC.

\section{Forced Degradation Study of LEN \\ Hydrolytic Degradation Study}

The $10 \mathrm{mg}$ LEN API and Lenangio ${ }^{\circledR}$ formulation equivalent to $10 \mathrm{mg}$ LEN were exposed to acid and base hydrolytic conditions in the presence of different concentration of $0.1,0.5$ and $1 \mathrm{~N} \mathrm{HCl}$ and $\mathrm{NaOH}$. Identical treatment was given to the marketed formulation of LEN. Both API as well as its marketed formulation were subjected to acidic and basic stress condition at $60^{\circ} \mathrm{C}$ and periodically samples were withdrawn and neutralized with opposite stressor prior to injecting into HPLC after appropriate dilution. A similar procedure was employed to study the forced degradation behaviour to study neutral hydrolysis where water was taken as neutral stressor.

\section{Peroxide degradation study}

To perform peroxide degradation, LEN and its formulation were subjected to $3 \% \mathrm{H}_{2} \mathrm{O}_{2}$ and $10 \% \mathrm{H}_{2} \mathrm{O}_{2}$ condition at room temperature and $60^{\circ} \mathrm{C}$ and the aliquots were withdrawn periodically and analysed by HPLC after proper dilutions.

\section{Thermal degradation study}

To explore the stability profile of LEN at different temperature, $10 \mathrm{mg}$ pure API and its formulation equivalent to $10 \mathrm{mg}$ LEN were spread uniformly on the petri plates individually, and exposed to a harsher dry heat condition i.e. at $80^{\circ} \mathrm{C}$ for 10 days in hot air oven. The samples were withdrawn at 2 and 10 days followed by HPLC analysis.

\section{Photolytic Degradation Study}

$10 \mathrm{mg}$ of API and formulation (equivalent to $10 \mathrm{mg}$ LEN) were exposed to $5382 \mathrm{LUX}$ and $144 \mathrm{UW} / \mathrm{cm}^{2}$ for 10 days and the degradation samples were subjected to analysis after suitable dilutions.

\section{Development of Stability Indicating Assay Method (SIAM)}

Aforesaid forced degradation samples were diluted appropriately to get the final concentration of $100 \mu \mathrm{g} / \mathrm{mL}$ individually and analysed separately to study degradation patterns of LEN in various harsher conditions and the $\%$ degradation was find out using below equation 1. Furthermore, equal volume of each forced degradation solutions were mixed together and diluted to $1 \mathrm{~mL}$. This mixture of stress solution was injected in HPLC to check the efficiency of the developed method to separate 
all the DPs selectively having resolution of more than 2 along with least asymmetry.

$$
\% \text { Drug degraded }=\frac{\begin{array}{c}
\text { Area of unstressed sample }- \\
\text { Area of stressed sample }
\end{array}}{\text { Area of unstressed sample }} \times 100
$$

\section{Method Validation}

Developed and optimized RP-HPLC method was validated successfully as per ICH guideline Q2(R1) for different parameters. ${ }^{16}$ Linearity was carried out taking different concentration ranging from 10 to $100 \mu \mathrm{g} / \mathrm{mL}$. Regression equation was generated and regression coefficient $\left(\mathrm{R}^{2}\right)$ value was calculated. The standard addition method was employed to express accuracy of method by incorporating known amount of LEN corresponding to 80,100 and $120 \%$ to fixed concentration of LEN formulation and the results were expressed in terms of standard deviation (SD) and percent relative standard deviation (\%RSD). Additionally, the precision of the method was studied at three different levels i.e. at lower quality control (LQC), medium quality control (MQC) and higher quality control (HQC) level. Limit of detection (LOD) and quantitation (LOQ) was figured out based on standard deviation of the response and slope method considering the equation 2 and 3.

$$
\begin{aligned}
& \text { LOD }: 3.3 \frac{\sigma}{\mathrm{S}} \\
& \mathrm{LOQ}: 10 \frac{\sigma}{\mathrm{s}}
\end{aligned}
$$

Where, stands for the SD of response and S for the SD of slope. Moreover Specificity was recognised by determining drug peak from its nearest resolved peak. Selectivity of the method was mentioned in terms of peak purity of drug peak and the peaks of DPs as well. The system suitability study was conducted injecting a $100 \mu \mathrm{g} / \mathrm{mL}$ LEN solution for six times and SD and $\%$ RSD was calculated for different parameters like retention time, theoretical plates and asymmetry. Finally the robustness of developed method was performed implementing a QbD method. For this purpose FFD Res III design $2^{\wedge 5-2}$ was used, where the factors were varied over at two levels -1 and +1 denoting the minimum level and maximum level of a particular factor respectively.

\section{Reaction Kinetics Study}

This study was performed to determine the order of degradation kinetics under different stress conditions.
$100 \mu \mathrm{g} / \mathrm{mL}$ of LEN solution was stressed in $0.1,0.5$ and $1 \mathrm{~N} \mathrm{HCl}$ at 40,50 and $60^{\circ} \mathrm{C}$. Whereas, similar temperature condition was provided for studying the degradation kinetics profile in alkaline condition as well. Thus the reaction order was determined by performing degradation kinetics at higher stressor concentration and temperature range. Samples were withdrawn at predefined time interval and analysed by RP-HPLC method. Finally, the plots of \%drug remained vs time (for zero order reaction kinetics) and \%log drug remained vs time (for first order reaction kinetics) were plotted individually and $\mathrm{R}^{2}$ values were calculated to decide the order of degradation kinetics.

\section{Green Metrics Assessment}

Green metrics assessment was performed by three different techniques like HPLC-EAT, AMVI calculation and solvent treatment options by Ecosolvent ${ }^{\circledR}$ tool. EAT tool gives a final EAT score based on Environment health safety (EHS) assessment. Herein, the aqueous and organic modifier consumed starting from sample preparation step to letter in HPLC mobile phase were calculated and these values were entered into the software to get the final EAT score. AMVI (total solvent consumption) was calculated as per the equation 4 given by Hartman et al. ${ }^{3}$ AMVI gives the total amount of solvent consumed in the HPLC method. For the purpose of comparison, the method developed on Thermo $150 \times 4.6 \mathrm{~mm}$ GAC column was also applied to Waters $250 \times 4.6 \mathrm{~mm}$ column.

$$
\begin{aligned}
\text { AMVI }= & \sum \text { sample prep solvent }+ \\
& \sum \mathrm{HPCl} \text { solvent } \times \text { No. of replicates }
\end{aligned}
$$

The Ecosolvent software ${ }^{\circledR}$ gives the better treatment option for the solvent waste generated amongst incineration or distillation. Initially, methanol was selected as a green solvent based on GSK SSG.

\section{Analysis of Formulation}

LEN formulation was analyzed to obtain \%assay value. Capsule shell of Lenangio ${ }^{\circledR}$ was removed and the content was emptied into $\mathrm{MeOH}$ to extract the LEN. This was followed by filtration and the filtrate was collected. Eventually, the $100 \mu \mathrm{g} / \mathrm{mL}$ LEN solution was prepared and analyzed by HPLC. The results i.e. HPLC area for $100 \mu \mathrm{g} / \mathrm{mL}$ LEN formulation obtained was compared with $100 \mu \mathrm{g} / \mathrm{mL}$ LEN API solution. The experiment was repeated for six times and \%assay was calculated using following equation 5 .

$$
\% \text { Assay }=\frac{\text { Area of LEN in formulation }}{\text { Area of LEN in API solution }} \times 100
$$




\section{Prediction of Probable DPs and Degradation Pathway}

DPs generated in different stressed conditions were subjected to LC-MS/MS analysis equipped with photo diode array (PDA) detector. The study was conducted on the Thermo ${ }^{\circledR}$ C-18 RP-HPLC column with the mobile phase of ammonium acetate (10 mM; pH 5). Solutions of each DPs were injected individually, scanned for entire wavelength range from 200 to $400 \mathrm{~nm}$ and molecular weight with its fragmentation product was obtained. This data were utilized to predict the probable degradation pathway by studying its degradation mechanism to predict possible structures of DPs.

\section{RESULTS AND DISCUSSION}

\section{RP-HPLC Method Development}

RP-HPLC method was developed and optimized implementing one factor at a time (OFAT) strategy. The results obtained after extensive trials taken using different buffers and organic modifier favoured a combination of ammonium acetate buffer having a $\mathrm{pH}$ of 5 and $\mathrm{MeOH}$ as mobile phase composition which satisfied all criteria vir:, optimum retention time which could separate the DPs with higher resolution having least tailing factor and higher number of theoretical plates. This method showed retention time of $7.91 \mathrm{~min}$ with a theoretical plate of 6672 having asymmetry of 0.98 as displayed in following Figure 2 and summarized in Table 1.

\section{Stress Degradation Study:}

The degradation study was performed in an acid hydrolytic condition using $0.5 \mathrm{~N} \mathrm{HCl}$ at $60^{\circ} \mathrm{C}$. The chromatogram obtained demonstrated two additional peaks. The two degradation product were eluted at retention time of $3.9 \mathrm{~min}$ and $4.7 \mathrm{~min}$ and labelled as DP-I and DP-II respectively (Figure 3a).

Additionally, the alkaline hydrolytic degradation was performed in $0.5 \mathrm{~N} \mathrm{NaOH}$ at $60^{\circ} \mathrm{C}$. This gave two DPs at similar retention times as mentioned earlier and portrayed in Figure 3b. Thus, the DPs formed under

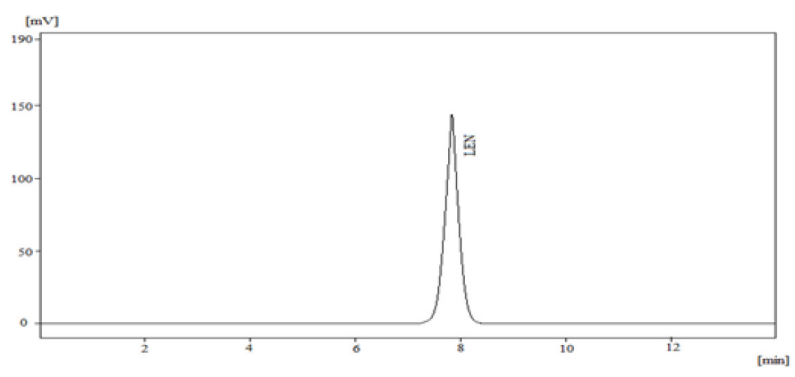

Figure 2: RP-HPLC chromatogram for LEN.

\begin{tabular}{|c|c|}
\hline \multicolumn{2}{|c|}{ Table 1: Optimized RP-HPLC method. } \\
\hline Parameters & Values \\
\hline Column type & $\begin{array}{c}\text { Thermo Scientific } \mathrm{C} 18 \text { column } \\
(150 \times 4.6 \mathrm{~mm} ; 3 \mu)\end{array}$ \\
\hline Buffer type & $\begin{array}{c}\text { Ammonium acetate } \\
(10 \mathrm{mM} ; \mathrm{pH}: 5)\end{array}$ \\
\hline Mobile phase composition & $\begin{array}{c}\text { Ammonium acetate: } \\
\text { MeOH::85:15 }\end{array}$ \\
\hline Flow rate (mL/min) & 1 \\
\hline Retention time (min) & 7.91 \\
\hline Asymmetry factor & 0.98 \\
\hline Theoretical plates & 6672 \\
\hline
\end{tabular}

\begin{tabular}{|c|c|c|c|c|}
\hline Condition & Parameters & Drug & DP-I & DP-II \\
\hline \multirow{6}{*}{$\begin{array}{c}\text { Acid } \\
(0.5 \mathrm{~N} \mathrm{HCl} \text { at } \\
\left.60^{\circ} \mathrm{C}\right)\end{array}$} & Retention time (min) & 7.9 & 3.9 & 4.7 \\
\hline & Tailing factor & 0.98 & 1.2 & 1.1 \\
\hline & Resolution & - & 5.96 & 9.17 \\
\hline & Peak purity index & 1.000 & 0.996 & 0.998 \\
\hline & $\begin{array}{l}\text { Number of theoretical } \\
\text { plates }\end{array}$ & 4820 & 3589 & 4201 \\
\hline & $\%$ Remaining & 80 & 16 & 14 \\
\hline \multirow{6}{*}{$\begin{array}{c}\text { Base } \\
(0.5 \mathrm{~N} \mathrm{NaOH} \text { at } \\
\left.60^{\circ} \mathrm{C}\right)\end{array}$} & Retention time (min) & 7.9 & 3.9 & 4.7 \\
\hline & Tailing factor & 0.98 & 1.3 & 1.3 \\
\hline & Resolution & - & 6.14 & 9.48 \\
\hline & Peak purity index & 1.000 & 0.995 & 0.991 \\
\hline & $\begin{array}{l}\text { Number of theoretical } \\
\text { plates }\end{array}$ & 4818 & 3214 & 4058 \\
\hline & \%Remaining & 75 & 20 & 15 \\
\hline $\begin{array}{c}\text { Peroxide } \\
\text { degradation ( } 3 \% \\
\left.\mathrm{H}_{2} \mathrm{O}_{2} \text { at } 60^{\circ} \mathrm{C}\right) \\
\end{array}$ & \multicolumn{4}{|c|}{ No degradation was envisaged } \\
\hline $\begin{array}{c}\text { Thermal } \\
\text { degradation }\end{array}$ & \multicolumn{4}{|c|}{ No degradation was envisaged } \\
\hline $\begin{array}{l}\text { Photolytic } \\
\text { degradation }\end{array}$ & \multicolumn{4}{|c|}{ No degradation was envisaged } \\
\hline
\end{tabular}

acidic hydrolytic conditions were also labelled as DP-I and DP-II.

The degradation study in neutral condition showed no extra peak other than the peak of LEN. Similarly, an extensive degradation study gave thermal, peroxide and photolytic stable to LEN as no degradation was envisaged in dry heat, photolytic and peroxide condition (Figure 3c-f). DP-I and DP-II obtained in acidic and basic hydrolysis were further characterized by LC-MS/MS. The summary of forced degradation behaviour of LEN is listed in following Table 2. Mixture of all degradation condition 

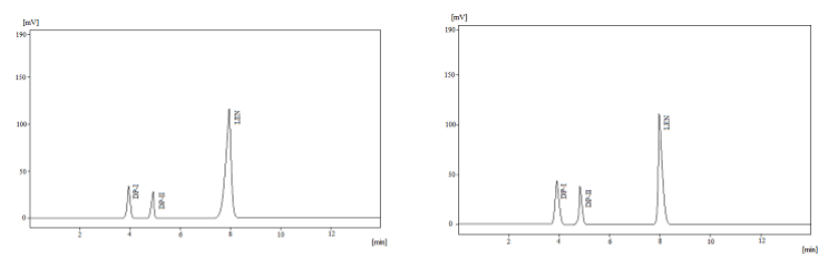

(a)

(b)

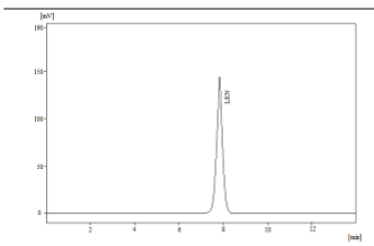

(c)

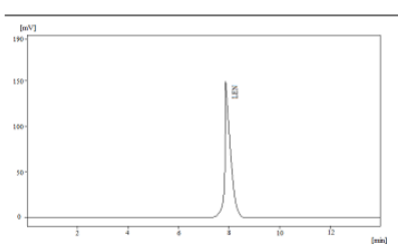

(e)

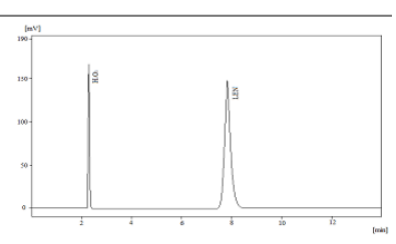

(d)

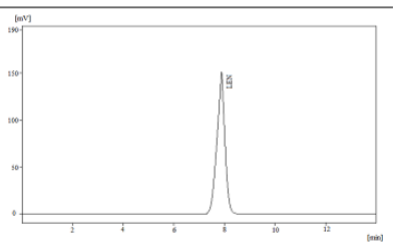

(f)

Figure 3: LEN chromatogram in (a) $0.5 \mathrm{~N} \mathrm{HCl}$, (b) $0.5 \mathrm{~N} \mathrm{NaOH}$, (c) Neutral, (d) peroxide, (e) thermal and (f) photolytic degradation condition.

\begin{tabular}{|c|c|c|}
\hline \multicolumn{2}{|c|}{ PARAMETERS } & VALUE \\
\hline \multicolumn{2}{|c|}{ Linearity $(\mu \mathrm{g} / \mathrm{mL})$} & $10-100$ \\
\hline \multicolumn{2}{|c|}{ Regression equation } & $67.85 x-0.0667$ \\
\hline \multicolumn{2}{|c|}{ Regression coefficient $\left(\mathrm{R}^{2}\right)$} & 0.998 \\
\hline \multirow{3}{*}{ \%Recovery } & $80 \%$ & $101.66 \pm 1.52$ \\
\hline & $100 \%$ & $99.30 \pm 0.577$ \\
\hline & $120 \%$ & $101.54 \pm 1.67$ \\
\hline \multicolumn{2}{|c|}{ Intra-day precision (\%RSD) } & 0.224 \\
\hline \multicolumn{2}{|c|}{ Inter-day precision (\%RSD) } & 0.175 \\
\hline \multicolumn{2}{|c|}{$\operatorname{LOD}(\mu \mathrm{g} / \mathrm{mL})$} & 0.040 \\
\hline \multicolumn{2}{|c|}{$\mathrm{LOQ}(\mu \mathrm{g} / \mathrm{mL})$} & 0.122 \\
\hline \multicolumn{2}{|c|}{$\%$ Assay } & $99.6 \pm 1.57$ \\
\hline
\end{tabular}

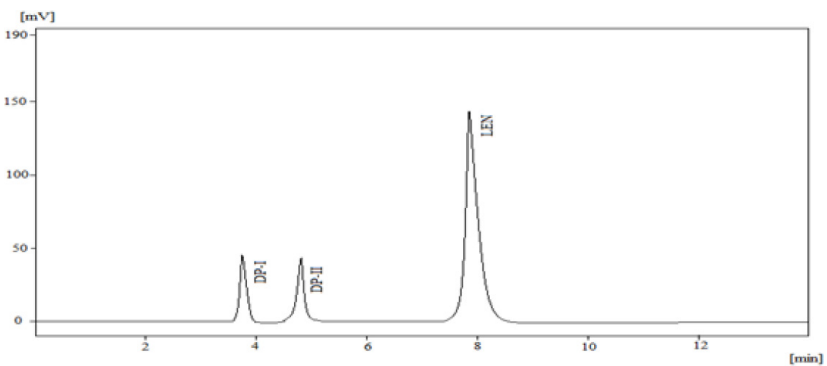

Figure 4: Final chromatogram of the developed SIAM.

also gave two DPs on the same retention time as obtained earlier as displayed in the following Figure 4.

\section{Validation of RP-HPLC Stability Indicating Assay Method}

Validation of HPLC method was carried out for different parameters like linearity, accuracy, precision (inter-day and intra-day), LOD and LOQ. The details of validation parameters are discussed in following Table 3. $\%$ Assay of the formulation was also conducted and the results were found to be within the acceptance criteria.

Furthermore, a fractional factorial method DoE strategy was used to carry out robustness study as summarized in Table 4. The robustness was adjudged by employing Res III FFD. The design matrix used consisted of $2^{\wedge 5-2}$ with factors being varied over two levels viz minimum and maximum. The three dimension (3D) contour plots obtained were evident of the fact that there was no considerable variation and the developed method was quite robust. Total of five critical method parameters (CMPs) were selected viz., $\mathrm{pH}, \%$ aqueous, buffer strength, injection volume and flow rate each varied at two levels. Three critical quality attributes (CQAs) taken were retention time, number of theoretical plates and tailing factor. The desirability value obtained for all CQAs were 1. As indicated by green region of the 3D

\begin{tabular}{|c|c|c|c|c|c|c|c|c|}
\hline \multicolumn{10}{|c|}{ Table 4: Fraction factorial design matrix. } \\
\hline Number & $\begin{array}{c}\text { pH of acetate } \\
\text { buffer }\end{array}$ & $\begin{array}{c}\text { \%Aqueous } \\
\text { phase }\end{array}$ & $\begin{array}{c}\text { Buffer } \\
\text { Strength }\end{array}$ & $\begin{array}{c}\text { Flow Rate } \\
(\mathbf{m L} / \mathbf{m i n})\end{array}$ & $\begin{array}{c}\text { Injection } \\
\text { volume }(\boldsymbol{\mu L})\end{array}$ & $\begin{array}{c}\text { Retention } \\
\text { time }(\mathbf{m i n})\end{array}$ & $\begin{array}{c}\text { Theoretical } \\
\text { plates }\end{array}$ & $\begin{array}{c}\text { Tailing } \\
\text { factor }\end{array}$ \\
\hline 1 & 4.5 & 87 & 20 & 0.80 & 10 & 7.91 & 6672 & 1 \\
\hline 2 & 5.5 & 87 & 10 & 1.20 & 10 & 7.95 & 6672 & 0.96 \\
\hline 3 & 4.5 & 87 & 10 & 0.80 & 20 & 7.85 & 6671 & 0.97 \\
\hline 4 & 4.5 & 83 & 20 & 1.20 & 10 & 7.86 & 6670 & 1.02 \\
\hline 5 & 5.5 & 83 & 20 & 0.80 & 20 & 7.87 & 6673 & 1.03 \\
\hline 6 & 5.5 & 83 & 10 & 0.80 & 10 & 7.88 & 6673 & 0.99 \\
\hline 7 & 5.5 & 87 & 20 & 1.20 & 20 & 7.89 & 6672 & 1.04 \\
\hline 8 & 4.5 & 83 & 10 & 1.20 & 20 & 7.90 & 6673 & 0.94 \\
\hline
\end{tabular}




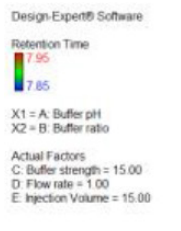

(A)
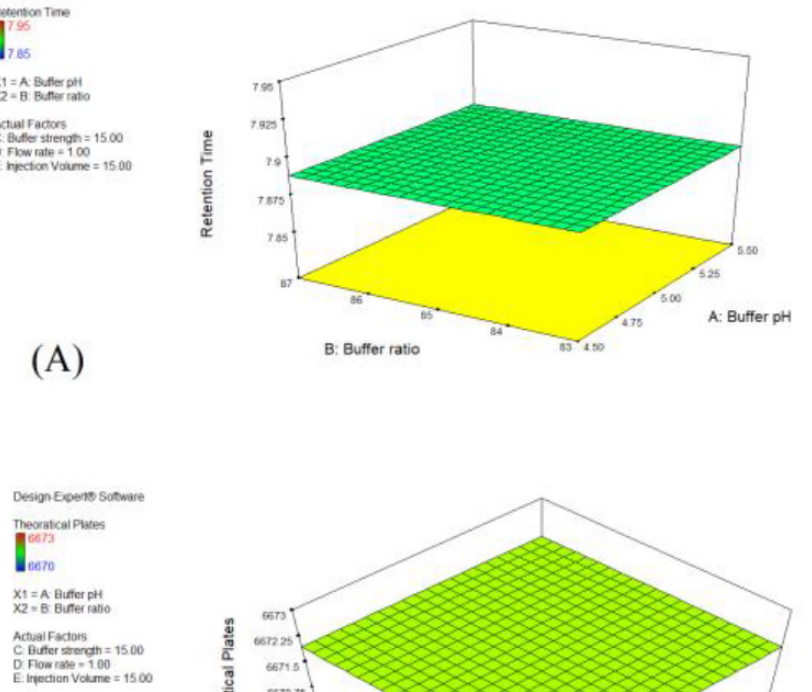

(B)

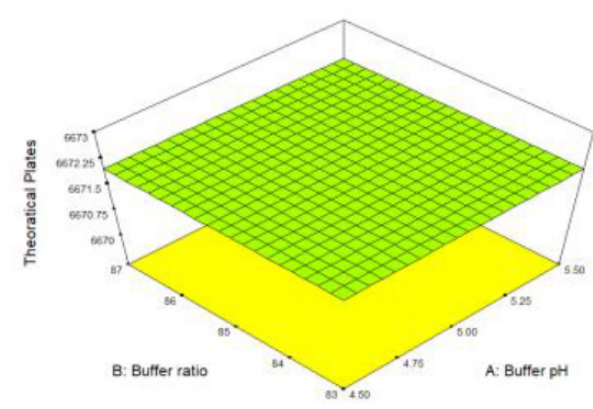

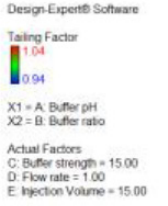

(C)

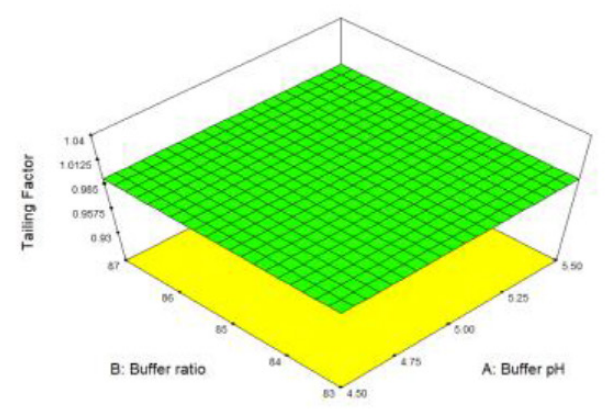

Figure 5: 3D surface plots showing effect of various parameters on various CQAs.

surface plots and also the curvature is flat which indicates that the developed method is cent percent robust (Figure 5).

\section{Greenness Assessment of the Developed Method}

\section{HPLC-EAT Assessment}

The EAT score based on EHS aspects was calculated by the HPLC-EAT tool. ${ }^{2}$ It gave a score of 32.195 (Figure 6). Which is quite lower when compared to other methods found in literature employing ACN in their methods. They had a score of 92.907 and 151.988 . The higher scores indicate a non-green method, which is in turn not environmentally and EHS favourable. The
(A)

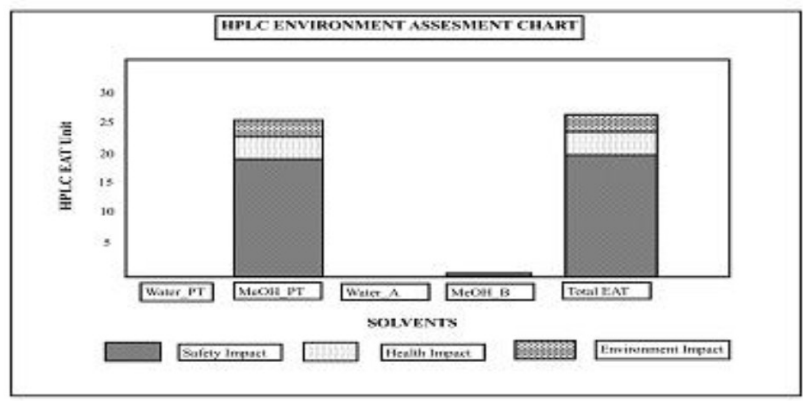

(B)

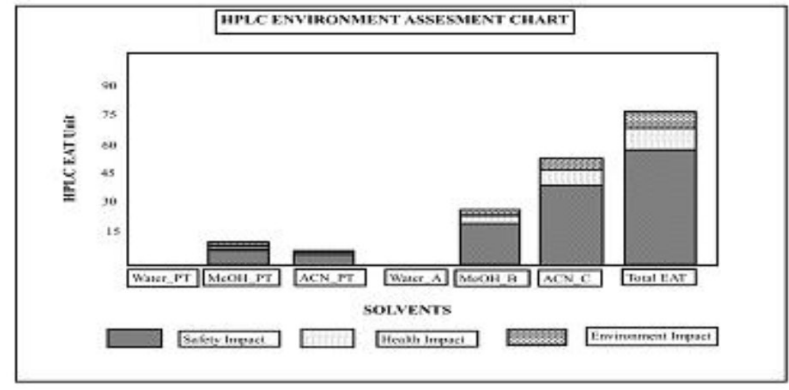

(C)

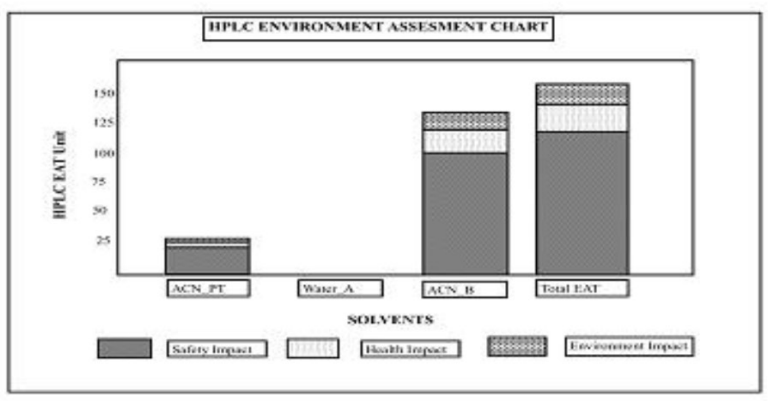

Figure 6: (a) HPLC EAT score of developed method (Acetate buffer: Methanol 85:15); (c) literature method (mobile phase A:Water; Mobile phase B: ACN: MeOH::55:45) [14] and (b) literature method (phosphate buffer: ACN::30:70).

low EHS score supports the claim of a successfully developed green HPLC method for LEN.

\section{AMVI}

AMVI (total solvent consumption) was calculated as per the equation 4 mentioned earlier. AMVI gives the total amount of solvent consumed in the HPLC method. For the purpose of comparison, the method developed on Thermo ${ }^{\circledR} 150 \times 4.6 \mathrm{~mm}$ GAC column was also applied to Waters ${ }^{\circledR} 250 \times 4.6 \mathrm{~mm}$ column. There was significant difference in the AMVI obtained for both the columns. For GAC narrow bore column the AMVI obtained was $34 \mathrm{~mL}$, whereas for later it was found to 
be $45 \mathrm{~mL}$. Notably, AMVI considers waste coming from sample preparation and from the operation of analytical instrument itself. On a small scale this may seem to be a minor difference but considering the whole scenario and amount of waste generated by all industries, this concept if implemented will prove to be highly useful. Thereby, reducing the harmful impact on environment to a greater extent.

\section{Solvent Treatment Options}

The solvent waste generated can be treated in various ways. Two main solvent treatment options are incineration and distillation. The best treatment option was suggested by Ecosolvent ${ }^{\circledR}$ software. The level 2 report generated was based on Eco-indicator 99 (EI99 points) scale. It suggested that for the present method incineration was an environmentally superior option as compared to distillation (Figure 7).

\section{Reaction Kinetics Study}

Reaction kinetics study performed for acid and base hydrolytic condition at different temperature vir, 40, 50 and $60^{\circ} \mathrm{C}$ taking different stressor concentration revelaed that the degradation kinetics was following zero order reaction kinetics. \%Concentration, \% og $\mathrm{C}_{\mathrm{o}}$ (logarithm of initial concentration) and $\% \log C_{t}(\log a r i t h m$ of concentration remained after time $(t)$ for each solution at different temperature and concentration was calculated.

\section{ECOSOLVENT}

Level 2 Impact Assessment Report Eco-Indicator 99 [ El99 Points ]

Comparison

\begin{tabular}{|ll} 
Distillation versus & Incineration \\
Simulation Mode: & Screening \\
Assessment Method: & Eco-Indicator 99 [ El99 Points ] \\
Report Conclusion: & Incineration is anvironmentally superior to Distlllation
\end{tabular}

Figure 7: Environment Impact Assessment report.
The plots of \%drug remained vs time and $\%$ log drug remained vs time demonstrated that higher $\mathrm{R}^{2}$ value for zero order reaction kinetics. The summary for the same is tabulated in Table 5 ad portrayed in Figure 8. From the reaction kinetics study it was concluded that degradation kinetics followed zero order kinetics for each degradation conditions as the $\mathrm{r}^{2}$ value for this reaction order was nearer to unity.

\section{Prediction of Probable Degradation Pathway}

Probable degradation pathway and structure was determined from the LC-MS/MS data shown in Figure 9 and 10 for DP-I and DP-II in acidic and alkaline stress condition. Mass analysis for acid stressed solutions is displayed in below Figure 9. LC-MS/MS study for DP-I revealed molecular weight of $278.0 \mathrm{gm} / \mathrm{mol}$ which was further fragmented to give product with the molecular weight of $260.8 \mathrm{gm} / \mathrm{mol}$. Likewise, mass analysis of DP-II exhibited $278.0 \mathrm{gm} / \mathrm{mol}$ molecular mass for parent ion along with $260.8 \mathrm{gm} / \mathrm{mol}$ molecular weight for daughter ion (Figure 10). Identical results were acquired for the LEN solution stressed with alkaline solution. Thus, it could be assumed that two DPs formed in acidic and alkaline condition at 3.9 and 4.7 min were identical as they are having similar molecular weight. Furthermore, in depth analysis revealed similar mass weight for DP-I and DP-II. This could be due to isomeric nature of both DPs. The probable degradation mechanisms along with the structure of DPs are postulated in following degradation mechanism scheme (Figure 11). Further confirmation could not be done, which needed isolation and spectral studies as this was beyond the scope of this study.

\section{CONCLUSION}

A green and robust stability indicating assay method was developed for model anti-cancer drug LEN. The greenness assessment of the developed method was carried out by various techniques. The low EAT score,

\begin{tabular}{|c|c|c|c|c|c|c|c|}
\hline \multirow{2}{*}{ CONDITION } & \multirow{2}{*}{ CONCENTRATION } & \multicolumn{2}{|c|}{$R^{2}$ at $40{ }^{\circ} \mathrm{C}$} & \multicolumn{2}{|c|}{$\mathrm{R}^{2}$ at $50^{\circ} \mathrm{C}$} & \multicolumn{2}{|c|}{$\mathrm{R}^{2}$ at $60^{\circ} \mathrm{C}$} \\
\hline & & ZERO & FIRST & ZERO & FIRST & ZERO & FIRST \\
\hline \multirow{3}{*}{ ACID } & 0.1 & 0.991 & 0.538 & 0.985 & 0.415 & 0.986 & 0.617 \\
\hline & 0.5 & 0.990 & 0.486 & 0.992 & 0.438 & 0.986 & 0.635 \\
\hline & 1 & 0.987 & 0.472 & 0.993 & 0.489 & 0.993 & 0.624 \\
\hline \multirow{4}{*}{ BASE } & 0.1 & 0.991 & 0.328 & 0.985 & 0.630 & 0.993 & 0.578 \\
\hline & 0.5 & 0.995 & 0.647 & 0.992 & 0.582 & 0.998 & 0.523 \\
\hline & 1 & 0.993 & 0.592 & 0.993 & 0.611 & 0.991 & 0.547 \\
\hline & $10 \%$ & 0.988 & 0.417 & 0.991 & 0.497 & 0.991 & 0.566 \\
\hline
\end{tabular}



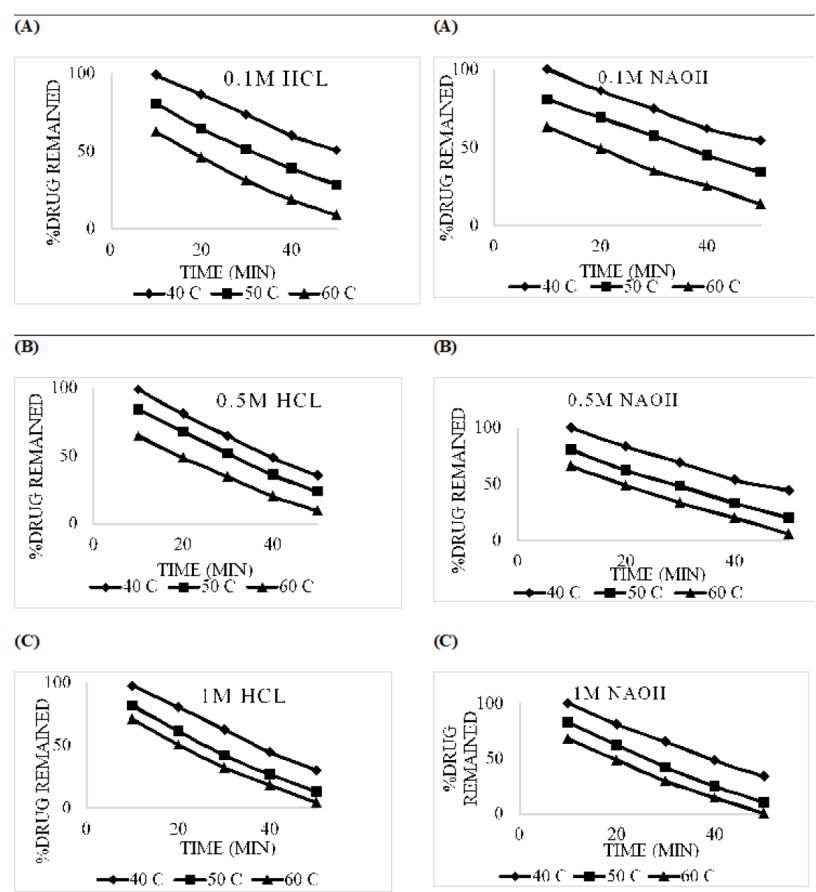

(C)

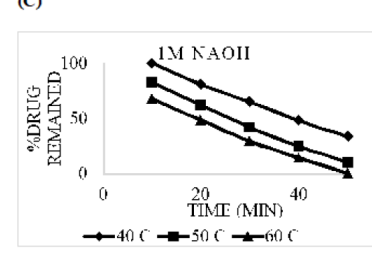

Figure 8 (a): Reaction kinetics study of LEN in (a) $0.1 \mathrm{M} \mathrm{HCl}$, (b) $0.5 \mathrm{M} \mathrm{HCl}$ and (a) $1 \mathrm{M} \mathrm{HCl}$ at 40,50 and $60^{\circ} \mathrm{C}$; (b). Reaction kinetics study of LEN in (a) $0.1 \mathrm{M} \mathrm{NaOH}$, (b) $0.5 \mathrm{M} \mathrm{NaOH}$ and (a) $1 \mathrm{M} \mathrm{NaOH}$ at 40,50 and $60^{\circ} \mathrm{C}$.

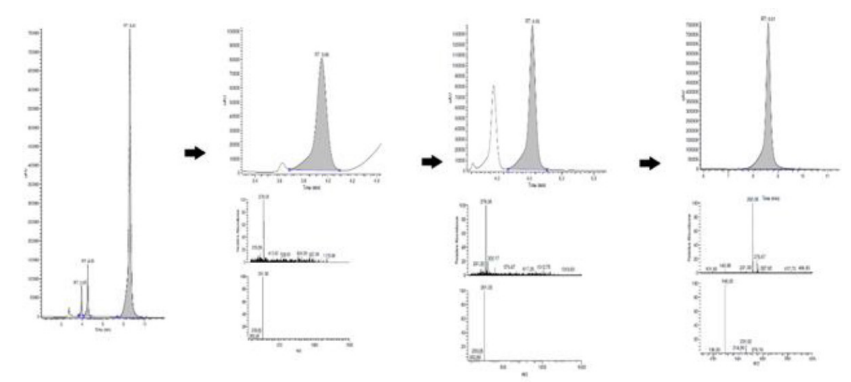

Figure 9: LC-MS/MS analysis of drug along with DP-I and DP-II in $0.5 \mathrm{~N} \mathrm{HCl}$.

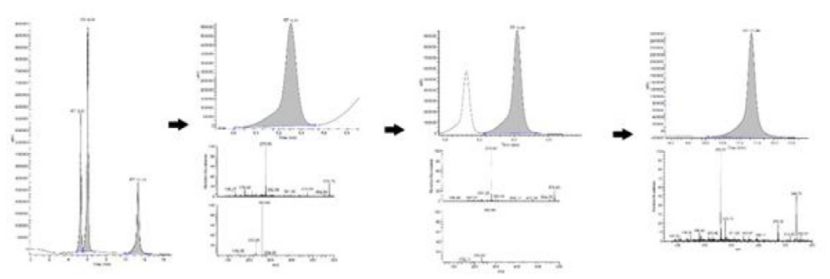

Figure 10: LC-MS/MS analysis of drug along with DP-I and DP-II in $0.5 \mathrm{~N} \mathrm{NaOH}$.

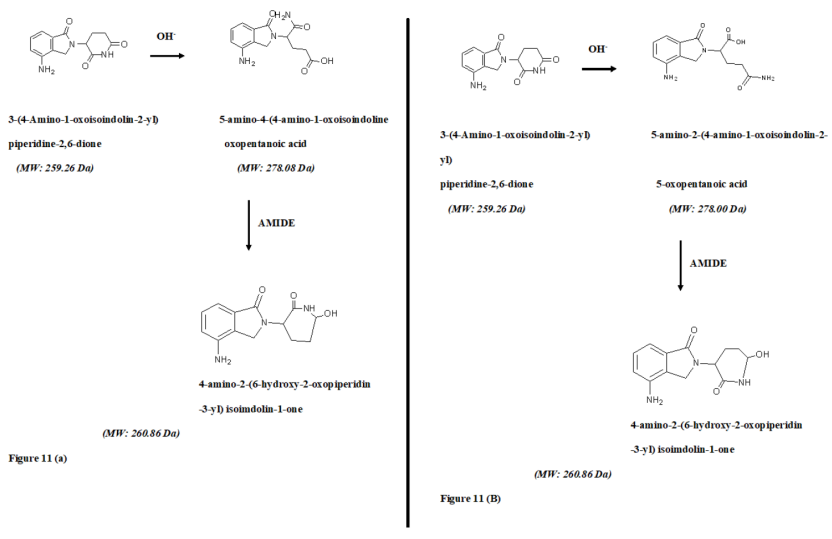

Figure 11: Degradation mechanism for (a) DP-I and (b) DP-II.

supported by lower AMVI value for the GAC column employed confirmed the success of the green method development. Incineration was found to be a better option for treatment of the solvent waste generated. The robustness of the developed method was adjusted by application of QbD using Res III FFD. Degradation kinetics study revealed that degradation followed a zero order kinetics. The drug was found to be stable in oxidative, thermal and photochemical stress conditions. However, two DPs were obtained under acid and base hydrolytic conditions. The two DPs obtained were labelled as DP-I and DP-II. Their probable structures and degradation pathway was predicted based on the LC-MS/MS data obtained. The probability was high that both the DP's were isomers of each other as concluded from the LC-MS/MS fragmentation pattern. However, this can be further confirmed by NMR analysis. Thus, a synergistic combination of both the concepts was successfully applied to the HPLC method development giving a highly robust and environmentally benign stability indicating assay method for LEN. If encouraged or applied on large scale these concepts in combination can do wonders economically and can be considered a leap forward in our efforts towards saving the environment.

\section{ACKNOWLEDGEMENT}

The author would like to thanks Apicore Pharmaceutical Ltd, Vadodara, India for providing a LEN gift sample. We are also thankful to AICTE, India for providing funds for carrying out the research work.

\section{CONFLICT OF INTEREST}

The authors declare no conflict of interest.

\section{ABBREVIATIONS}

$\% \log \mathrm{C}_{0}$ : Logarithm of initial concentration; $\% \log$ $\mathbf{C}_{\mathbf{t}}$ : Logarithm of concentration remained after time 
(t); \%RSD: Relative standard deviation; ACN: Acetonitrile; AMVI: Analytical method volume intensity; API: Active pharmaceutical ingredient; CMPs: Critical method parameters; CQAs: Critical quality attributes; DoE: Design of experiments; DPs: Degradation products; EAT: Environment assessment tool; EHS: Environment health safety; FFD: Fractional factorial design; GAC: Green analytical chemistry; GSK $^{\circledR}$ : Glaxo smith kline; $\mathbf{H}_{2} \mathbf{O}_{2}$ : Hydrogen peroxide; $\mathbf{H C l}$ : Hydrochloric acid; HQC: Higher quality control; ICH: International Conference on Harmonisation; LEN: Lenalidomide; LOD: Limit of detection; LQC: Lower quality control; MeOH: Methanol; MQC: Medium quality control; $\mathbf{N a O H}$ : Sodium hydroxide; PDA: Photo diode array; QbD: Quality by Design; $\mathbf{R}^{2}$ : Regression co-efficient; RP-HPLC: Reverse Phase high pressure liquid chromatography; SD: Standard deviation; SIAM: Stability indicating assay method; SSG: Solvent selection guide.

\section{REFERENCES}

1. Welch CJ, Wu N, Biba M, Hartman R, Brkovic T, Gong X, et al. Greening analytical chromatography. TrAC Trends in Analytical Chemistry. 2010;29(7):667-80.

2. Gaber $Y$, Törnvall U, Kumar M, Amin MA, Hatti-Kaul R. HPLC-EAT (Environmental Assessment Tool): a tool for profiling safety, health and environmental impacts of liquid chromatography methods. Green Chemistry. 2011;13(8):2021-5.

3. Hartman R, Helmy R, Al-Sayah M, Welch CJ. Analytical method volume intensity (AMVI): a green chemistry metric for HPLC methodology in the pharmaceutical industry. Green Chemistry. 2011;13(4):934-9.

4. Jimenez-Gonzalez C, Curzons AD, Constable DJ, Cunningham VL. Expanding GSK's solvent selection guide-application of life cycle

PICTORIAL ABSTRACT

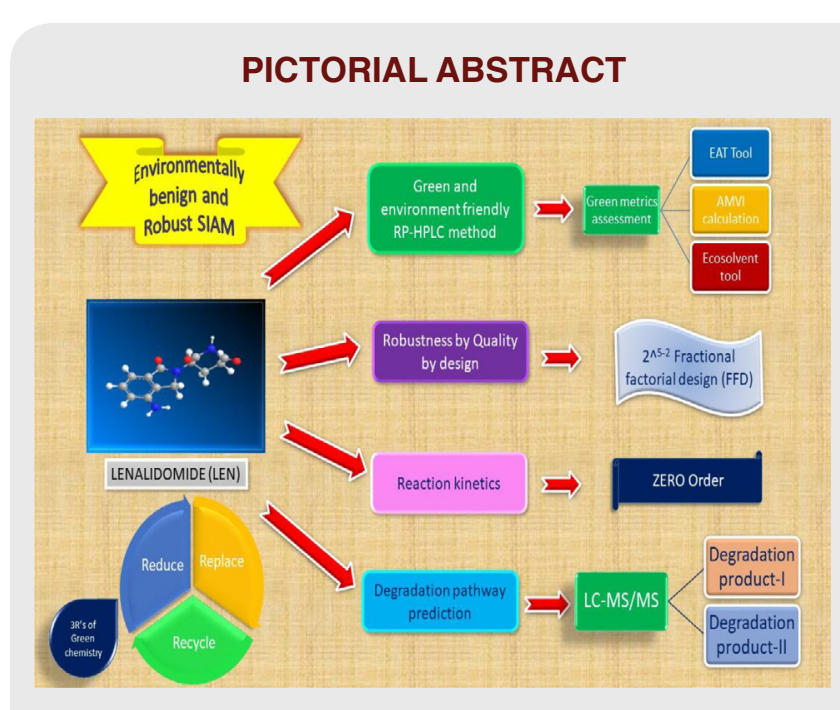

assessment to enhance solvent selections. Clean Technologies and Environmental Policy. 2004;7(1):42-50.

5. Capello C, Fischer U, Hungerbühler K. What is a green solvent? A comprehensive framework for the environmental assessment of solvents. Green Chemistry. 2007;9(9):927-34.

6. Peraman R, Bhadraya K, Padmanabha RY. Analytical quality by design: a tool for regulatory flexibility and robust analytics. International Journal of Analytical Chemistry. 2015;2015.

7. Saroj S, Jairaj V, Rathod R. Applying green analytical chemistry for development and validation of RP-HPLC stability indicating assay method for estimation of fenoverine in bulk and dosage form using quality by design approach. Journal of Liquid Chromatography and Related Technologies. 2017;40(7):340-52.

8. Seema DS, Priya S, Vinod J, Rajeshwari R. Green Analytical Chemistry and Quality by Design: A Combined approach towards Robust and Sustainable Modern Analysis. Current Analytical Chemistry. 2017;13:1-16.

9. Dimopoulos M, Spencer A, Attal M, Prince HM, Harousseau J L, Dmoszynska A, et al. Lenalidomide plus dexamethasone for relapsed or refractory multiple myeloma. New England Journal of Medicine. 2007;357(21):2123-32.

10. List A, Kurtin S, Roe DJ, Buresh A, Mahadevan D, Fuchs D, et al. Efficacy of lenalidomide in myelodysplastic syndromes. New England Journal of Medicine. 2005;352(6):549-57.

11. Sastry B, Gananadhamu S, Prasad S, Venu G. New spectrophotometric methods for estimation of lenalidomide in pharmaceutical formulations. Int $\mathrm{J}$ PharmTech Res. 2009;1:416-9.

12. Saravanan G, Rao B, Ravikumar M, Suryanarayana M, Someswararao N, Acharyulu P. Development of an HPLC assay method for lenalidomide. Chromatographia. 2007;66(3-4):287-90.

13. Khalil NY, Darwish IA, Wani TA, Al-Majed A RA. Trace determination of lenalidomide in plasma by non-extractive HPLC procedures with fluorescence detection after pre-column derivatization with fluorescamine. Chemistry Central Journal. 2013;7(1):52.

14. Reddy LM, Reddy KJ, Reddy LB, Reddy PR. Development of a rapid and sensitive HPLC assay method for lenalidomide capsules and its related substances. Journal of Chemistry. 2012;9(3):1165-74.

15. Pulla RP, Sastry B, Prasad YR, Raju廿 NA. http://jprsolutions. info. Journal of Pharmacy Research. 2011;4(4):1199-200.

16. Guideline IHT. Validation of analytical procedures: text and methodology Q2 (R1). 2005;1.

- The developed and validated RP-HPLC method was robust, selective and sensitive for Lenalidomide estimation in bulk. The combination of GAC and QbD approach was successfully used for estimation of LEN. The developed novel SIAM method was specific in nature and is able to detect the drug without any interference in presence of impurities. Furthermore, the detailed stress degradation study demonstrated formation of two degradation product i.e. DP-I and DP-II in acidic and basic hydrolytic condition demonstrated the presence of acid and base labile amide group which was unstable in hydrolytic conditions. Finally, the probable chemical structure, degradation kinetic and degradation mechanism was interpreted from the acquired LC-MS/MS data. 


\section{About Authors}

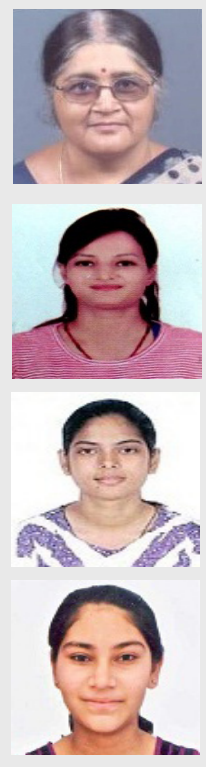

Sadhana Rajput is a Professor and Dean in Pharmaceutical Quality Assurance Department at Faculty of Pharmacy, The Maharaja Sayajirao University of Baroda. Her area of interest are Development of Analytical Methods, Impurity profiling, Development of modified release formulations and standardization of herbal formulations.

Juhi Saxena is working as a QA Executive in Research Quality Assurance Department at Sun Pharmaceuticals. In 2016, she completed her M.Pharm from The Maharaja Sayajirao University of Baroda in Pharmaceutical Quality Assurance department.

Seema Saroj is a Ph.D. research scholar working at The Maharaja Sayajirao University of Baroda enrolled in Pharmaceutical Quality Assurance Department under the Faculty of Pharmacy. She has completed her M.S.Pharm form NIPER-Ahmedabad. She is currently working on projects involving quality by design and green analytical chemistry concepts.

Priya Shah is a Ph.D. student of The Maharaja Sayajirao University of Baroda enrolled in Pharmaceutical Quality Assurance department under the Faculty of Pharmacy. She has completed her M.S.Pharm form NIPER-Ahmedabad. She is actively researching on cancer formulations and analysis. Her research work also involves in depth study of Quality by design methodology.

Cite this article: Saxena J, Saroj S, Shah PV, Rajput SJ. Development and Validation of an Environmentally Benign and Robust Stability Indicating Assay Method for Lenalidomide: Comprehensive Degradation Kinetics Study and Application of Synergistic Approach Involving Green Analytical Chemistry and Quality by Design Methodology. Indian J of Pharmaceutical Education and Research. 2019;53(1):133-43. 